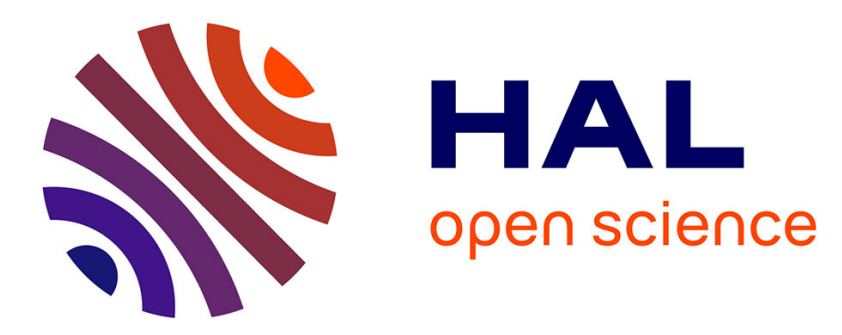

\title{
Spatial variation of trends in wildfire and summer drought in British Columbia, Canada, 1920-2000
}

Andrea Meyn, Sebastian Schmidtlein, Stephen Taylor, Martin Girardin, Kirsten Thonicke, Wolfgang Cramer

\section{To cite this version:}

Andrea Meyn, Sebastian Schmidtlein, Stephen Taylor, Martin Girardin, Kirsten Thonicke, et al.. Spatial variation of trends in wildfire and summer drought in British Columbia, Canada, 1920-2000. International Journal of Wildland Fire, 2010, 19 (3), pp.272-283. 10.1071/WF09055 . hal-01755887

\section{HAL Id: hal-01755887 \\ https://hal.science/hal-01755887}

Submitted on 19 Apr 2018

HAL is a multi-disciplinary open access archive for the deposit and dissemination of scientific research documents, whether they are published or not. The documents may come from teaching and research institutions in France or abroad, or from public or private research centers.
L'archive ouverte pluridisciplinaire HAL, est destinée au dépôt et à la diffusion de documents scientifiques de niveau recherche, publiés ou non, émanant des établissements d'enseignement et de recherche français ou étrangers, des laboratoires publics ou privés. 


\section{Spatial variation of trends in wildfire and summer drought in British}

\section{Columbia, Canada, 1920-2000}

\section{Short title: Trends in wildfire and summer drought in BC}

$4 \quad$ Andrea Meyn ${ }^{1}$, Sebastian Schmidtlein ${ }^{2}$, Stephen W. Taylor ${ }^{3}$, Martin P. Girardin ${ }^{4}$, Kirsten

$5 \quad$ Thonicke ${ }^{1}$ and Wolfgang Cramer ${ }^{1}$

$6 \quad{ }^{1}$ Earth System Analysis

$7 \quad$ Potsdam Institute for Climate Impact Research (PIK) e.V., Telegraphenberg A62

8 PO Box 6012 03, 14412 Potsdam, Germany

$9 \quad$ 2Department of Geography, University of Bonn, 53115 Bonn, Germany

$10{ }^{3}$ Natural Resources Canada, Canadian Forest Service, Pacific Forestry Centre, 506 West

11 Burnside Road, Victoria, BC, V8Z 1M5, Canada

$12{ }^{4}$ Natural Resources Canada, Canadian Forest Service, Laurentian Forestry Centre, 1055 du

13 P.E.P.S., PO Box 10380, Stn. Sainte-Foy, Quebec, QC, G1V 4C7, Canada

$14 *$ corresponding author:

15 Andrea Meyn

16 Research Domain Earth System Analysis

17 Potsdam Institute for Climate Impact Research (PIK) e.V., Telegraphenberg A62,

18 PO Box 6012 03, 14412 Potsdam, Germany;

19 Andrea.Meyn@pik-potsdam.de 


\section{Summary for table of contents}

2 A pronounced increase in fire activity over recent decades is consistent with projections of

3 future increase driven by climate warming in Canada. For Canada's most western province

4 British Columbia, we observed opposing trends: a decrease in wildfire activity that is

5 significantly related to wetter summers with the strength of the relationship considerably

6 varying between British Columbia's landscapes.

\section{Abstract}

8 Owing to large climatic and orographic variation, British Columbia covers a variety of

9 ecosystems extending from temperate rain forests on the Pacific coast to boreal forests in the

10 northeast. The aim of this study is to investigate the spatial variation of trends in wildfire

11 activity and their relationship to summer drought for the entire province of British Columbia.

12 Time series of monthly wildfire extent and occurrence, monthly self-calibrating Palmer

13 Drought Severity Index and monthly Aridity Index were derived from spatially explicit data.

14 Sixteen landscape regions according to the provincial Biogeoclimatic Ecosystem

15 Classification system served as spatial reference. The regional series for 1920-2000 were

16 subjected to trend analysis. Correlations between area burned and summer drought were

17 assessed and tested for significance. The observed decrease in wildfire activity is significantly

18 related to wetter summers with the strength of the relationship considerably varying between

19 British Columbia's landscapes. Our results suggest that aggregated statistics for large regions

20 with complex topography and climate can hide the spatial variation in direction and strength

21 of changes and may accordingly obscure the relationship between fire and drought. Based on

22 high-spatial-resolution data, our study is the first to provide a differentiated picture for British

23 Columbia. 
1 Keywords: area burned, aridity index, BEC, fire frequency, PDSI, self-calibrating PDSI 


\section{Introduction}

2 Several studies have shown a pronounced increase in fire activity comprising area burned and

3 fire occurrence for Canada over recent decades (Van Wagner, 1988; Podur et al., 2002; Gillett

4 et al., 2004; Xiao and Zhuang, 2007; Kasischke and Turetsky, 2006; Gillett et al., 2004). This

5 is consistent with projections about a future extension of the fire season (Stocks et al., 1998;

6 Wotton and Flannigan, 1993), and a doubling of annual area burned by the end of the 21 st

7 century in relation to climate warming (Flannigan et al., 2005). This being said, not all

8 Canadian boreal forests have experienced this change. Indeed, no widespread change of fire

9 risk and area burned has been observed in western Canada over the second half of the 20th

century (Amiro et al., 2004; Girardin and Wotton, 2009; Skinner et al., 1999). Rather,

analyses of 20th century trends in summer moisture data suggested that the region was

dominated by a significant trend toward decreasing dryness (Girardin and Wotton, 2009).

This is in agreement with Taylor et al. (2006) who reported a decrease in area burned in

British Columbia's pine forests since 1920, and with Masters (1990) who found a lower area projections ( $2 \mathrm{x} \mathrm{CO}_{2}$ scenario) also show considerable uncertainty with respect to fire risk in western Canada. While Flannigan et al. (1998) suggested a considerable regional variation in the response of the mean and maximum Fire Weather Index (FWI) with portions of BC showing a decrease, Flannigan et al. (2000) suggest an increase in the mean and maximum seasonal severity rating (SSR) for the entire province of $\mathrm{BC}$ with the strongest increase 21 occurring in coastal BC.

All these studies have a low spatial resolution (aggregated statistics for the entire province of $\mathrm{BC}$, ecozones or grids with a spatial resolution of $0.5^{\circ}, 5^{\circ}$ or $400 \mathrm{~km}$ ). Most cover a relatively short time period of about 50 years (Van Wagner 1988; Skinner et al. 1999; Podur 
1 Zhuang 2007) or are projections based on model runs (Wotton and Flannigan 1993; Flannigan

2 et al. 1998; Stocks et al. 1998; Flannigan et al. 2000; Flannigan et al. 2005). In regions with

3 complex terrain such as BC, the confidence of projections based on coarse-spatial-resolution

4 general circulation model (GCM) data is greatly reduced (Flannigan et al. 2000). Owing to

5 the large variety of ecosystems, regional climates and differences in land-use and settlement

6 history, it is also likely that trends in historical annual area burned and fire frequency vary

7 within BC and cannot be captured by coarse-scale climate projections. The goal of this study was to analyze the spatial variation in trends of historical area

9 burned in $\mathrm{BC}$ and their relationship with trends in summer drought. Fire and drought data of

10 high spatial and temporal resolution together with a relatively long period of investigation (81

11 years) allow for a differentiated picture for the first time. The results of this work set the basis

12 for a follow-up study (Meyn et al. 2009) that focusses on interannual variations in area burned and their relationships to climate oscillations and seasonal drought. 


\section{$1 \quad$ Material and Methods}

\section{Study area}

3 The study area encompasses the entire province of BC located in western Canada, which falls

4 between $\sim 48$ and $60^{\circ} \mathrm{N}$ of latitude and has a total land area of $\sim 950000 \mathrm{~km}^{2}$. The province is covered by the north-south-oriented Cordilleran mountain system of western North America,

6 except for the northeastern plains. Climatic conditions in $\mathrm{BC}$ vary primarily with proximity to

7 the Pacific Ocean, topography and latitude. While the Rocky Mountains restrict the westward

8 flow of cold continental arctic air masses from central Canada, the Coast Mountains represent

9 a barrier for the moisture-laden west winds. This situation creates a strong west-east gradient in precipitation and continentality as well as a distinct rain-shadow effect - mean annual

11 precipitation varies up to 20 times. Because of this climatic and orographic variation, the

12 study area includes a variety of ecosystems, ranging from temperate rainforests in the

13 southwest to boreal forests in the northeast. $\mathrm{BC}$ is divided into 16 sub-regions or zones

14 following the Biogeoclimatic Ecosystem Classification (BEC, Figure 1,Table 1; Meidinger and Pojar, 1991). BEC zones represent landscape types with a broadly homogeneous natural vegetation and climate. Our analysis is based on the assumption that landscape types with a broadly homogeneous natural vegetation and climate show a relatively homogeneous fire regime and relatively homogeneous drought patterns.

Fire data

21 The analyses used a digital, spatially explicit fire database developed by researchers from the

22 Canadian Forest Service, Pacific Forestry Centre, Victoria, and from the BC Ministry of

23 Forests and Range Research Branch using administrative fire records, forest inventories, and

24 remote-sensing data (Taylor and Thandi, 2003). The fire database contains all fires reported in 
1 BC between 1920 and 2000 (total of 16 559) that exceeded 20 ha in size (except for fires that

2 occurred in the national parks (about $4700 \mathrm{~km}^{2}$ ) and fires occurring in a strip of land $32 \mathrm{~km}$

3 on each side of the Canadian Pacific Railway between the Alberta border and Port Moody

4 before 1930 (about $30000 \mathrm{~km}^{2}$; Taylor and Thandi 2003). Fire records include date (of

5 discovery), location, extent and cause (person, lightning). For each BEC zone, the total area

6 burned during the study period 1920-2000 was calculated to give an impression over the

7 geographic distribution of fire within BC (Table 1). Then the annual proportion burned as

8 percentage of flammable area (for the remainder of the paper referred to as 'area burned'

9 except for figure legends and table headings) and the annual number of fires (fire frequency)

10 were calculated for the province of $\mathrm{BC}$ and for each BEC zone. Fire data for the province of

11 BC and for all zones show skewed distributions that significantly deviate from the normal

12 distribution (Shapiro-Wilk-W-test).

$B E C$ and landcover data

'Version 6 of the vector geographic information system (GIS) layer of the Biogeoclimatic Subzone/Variant Mapping was used (Research Branch, Ministry of Forests and Range 2006a). For detailed information on the biogeoclimatic classification system, please refer to http://www.for.gov.bc.ca/hre/becweb/ (accessed 24 January 2010) and Meidinger and Pojar (1991). We used landcover data based on an intersection of the biogeoclimatic classification with a provincial base map delineating the three classes: land, freshwater and permanent ice or snow (Research Branch, Ministry of Forests and Range 2006b, accessed 24 January 2010). Land (including urban areas and cropland) was considered to be the flammable portion of a zone (Table 1). 
2 Monthly mean temperature and precipitation data were computed by Wang et al. (2006) using

3 their scale-free climate model, ClimateBC. ClimateBC joins historical, monthly climate

4 variability data (CRU-TS 2.1 data (Mitchell and Jones, 2005)) with downscaled PRISM

5 monthly climate normal data (Daly et al., 2002). The latter are computed based on a statistical

6 regression model named parameter-elevation regressions on independent slopes model

7 (PRISM). PRISM comprises expert knowledge "on the spatial patterns of climate and their

8 relationships with geographic features" in the form of algorithms (Daly et al., 2002). This

9 model thus connects statistical methods and human expertise utilizing knowledge-based

10 system (KBS) technology as a basic structure (Daly et al., 2002). Data included into PRISM

11 are a digital elevation model, point station data, other spatial datasets, a knowledge base and

12 human-expert parameterisation (Daly et al., 2002). ClimateBC temperature and precipitation

13 data with a spatial resolution of $400 \mathrm{~m}$ were used to compute seasonal drought indices.

\section{Palmer Drought Severity Index data and Aridity Index data}

Two drought indices, the Palmer Drought Severity Index (PDSI) and the Aridity Index (AI)

were used in this study in order to test whether observed trends in summer drought are consistent.

The PDSI is one of the most commonly used indices that determine excesses or deficiencies of moisture availability in relation to average climate values at a specific location (http://www.srh.noaa.gov/jetstream/append/glossary_p.htm). It is thus standardized to local climatology (Shabbar and Skinner, 2004). The PDSI includes precipitation, potential and actual evapotranspiration, infiltration of water into the soil, and runoff

24 (http://www.srh.noaa.gov/jetstream/append/glossary_p.htm). PDSI values are divided into 11 
1 the calculation of the PDSI values are given by Palmer (1965) and Alley (1984) while Heim

2 (2002) reviews the most commonly used drought indices including the PDSI. For the purpose

3 of the present study, we used the self-calibrating PDSI of Wells et al. (2004). The self-

4 calibrating PDSI (scPDSI) replaces empirical constants in the index that lead to inconsistent

5 behaviour of the PDSI at various locations prohibiting spatial comparisons of PDSI values by

6 dynamically calculated values (Wells et al., 2004).

We calculated the monthly scPDSI based on ClimateBC monthly temperature and precipitation data (Hamann and Wang, 2005; Wang et al., 2006; for the period 1920-2000 with a spatial resolution of $400 \mathrm{~m}$ by adapting the $\mathrm{C}++-$-code of Wells et al. (2004) for single locations to grids.

Additional input data required for each grid cell were normal temperatures, latitude, and available water-holding capacity $(A W C)$ of the soil. The $A W C$ is needed as input for the water-balance equations, where it is used along with the potential evapotranspiration (PET) to determine the soil moisture status for each period of time. $A W C$ was downscaled to a resolution of $400 \mathrm{~m}$ from a data set of soil properties at $1^{\circ}$ resolution by Webb et al. (1993).

16 This map has been used before for coarse scale investigations on PDSI (Dai et al., 2004). It depicts clear relations between major landcover types and coarse-scale patterns in $A W C$, which were used for downscaling. The introduced error is necessarily large but likely minor compared with the error caused by keeping the values constant (e.g. Shabbar and Skinner, 2004) or by using a coarse-scale grid for relatively fine-scale investigations. Corresponding to 21 the work of Webb et al. (1993), areas with permanent snow and ice were assigned an $A W C=1$ mm while rocky alpine terrain was assigned $A W C=230 \mathrm{~mm}$. Ripe alpine and tundra soils received a value of $A W C=300 \mathrm{~mm}$ and the remaining forested and agricultural areas an $A W C$ $24=480 \mathrm{~mm}$. Built-up areas were treated like rocky terrain. For the calculations of the PDSI and the scPDSI, all precipitation is assumed to be in the liquid phase (Alley, 1984). Precipitation in the form of snow is not taken into account, nor 
1 are changes in the water-holding capacity of the soils when they freeze (Alley, 1984; van der

2 Schrier et al., 2006; van der Schrier et al., 2007). This limits the use of the scPDSI in regions

3 with significant seasonal snow cover. This being said, van der Schrier et al. (2007) showed

4 that seasonal snow cover has a negligible influence on summer scPDSI values. For these

5 reasons and because annual area burned is related most strongly to summer drought for most

6 of BC (Meyn et al. 2009), we limited the trend analyses to summer scPDSI. Summer scPDSI

7 for the flammable area of each zone and each year was calculated based on the monthly

8 values with summer defined as June-August (JJA). ScPDSI data were used to check whether

9 trends in annual proportion burned in a zone are related to trends in summer drought.

The aridity index (AI) was included in the analysis to test whether similar

\section{Analysis}

In order to detect increases in area burned that are potentially due to increasing mapping completeness, both area burned and fire frequency were analyzed for positive shifts in the mean according to the regime shift analysis of Rodionov (2006) because an increase in the number of reported fires can be a hint of incomplete mapping in earlier years. For trend analysis, we used the non-parametric Mann-Kendall trend test and the non parametric Theil- 
1 Sen approach. The relationship between fire and summer drought was investigated using

2 Spearman rank correlation analysis. These methods as well as how we dealt with positive autocorrelation occurring in some of the time series are described as follows.

Regime shift analysis was performed using Rodionov's regime shift detection software version 3.2 with the following parameters: probability level 0.05 , cut-off length $=20$ years, outliers weight parameter (Huber parameter) $=6$, subsample size $=12$; based on original area burned data with first-order autoregressive (AR1) correction in order to account for serial correlation within the data. The autoregressive parameter (AR1) estimation was based on the 'Inverse Proportionality with four corrections' (IP4) method, with the underlying assumption that the bias is approximately inversely proportional to the sample size (Rodionov 2006). For details on the method, see http://www.beringclimate.noaa.gov/regimes/.

To analyze whether annual fire data show a significant trend over the period 1920-2000, the Mann-Kendall trend test (Mann, 1945; Kendall, 1970) was applied taking autocorrelation into account. The slope of the trends was estimated based on the Theil-Sen approach (Theil, 1950; Sen, 1968). The Mann-Kendall trend test, a special case of the Kendall rank correlation test, is one of the most widely used non-parametric tests for trend detection in climatic and hydrological time series (Hamed and Rao, 1998; Andreadis and Lettenmaier, 2006). Non-parametric tests have the advantage that their significance and power is not affected by the actual distribution of the data (Hamed, 2008) because they are based on the ranks of the observations. This makes them less sensitive to outliers and thus more suitable for trend detection of time series that are skewed and may contain outliers (Hamed, 2008), such as fire data. The Mann-Kendall trend test evaluates the null hypothesis $\mathrm{H}_{0}$ that a time series $\left\{Y_{i}, i=1,2, \ldots, n\right\}$ is random (independent and identically distributed) against the alternative hypothesis $\mathrm{H}_{1}$ that $\mathrm{Y}$ exhibits a monotonic trend (Kendall, 1970). $\left\{R_{i}, \mathrm{i}=1,2, \ldots\right.$, $n\}$ are the corresponding ranks of the elements of the time series. The Kendall score, $S$, and its variance $V(S)$ are computed as follows: 
$1 \quad S=\sum_{i<j} \operatorname{sign}\left(\boldsymbol{R}_{j}-\boldsymbol{R}_{i}\right)$

2 where $R_{j}$ are the sequential ranks, $n$ is the number of observations and

$3 \operatorname{sign}\left(R_{j}-R_{i}\right)=\left\{\begin{array}{cll}1 & \text { if } & R i<R j \\ 0 & \text { if } & R i=R j \\ -1 & \text { if } & R i>R j\end{array}\right.$

4 Under the assumption of random values, the Kendall score is asymptotically normally

5 distributed with the mean zero and variance

$6 \quad V(S)=\frac{n(n-1)(2 n+5)-\sum_{m=1}^{n} t_{m} m(m-1)(2 m+5)}{18}$

7 where $m$ is the number of groups with equal observations (tied ranks), each with $t_{j}$ equal

8 observations (Mann, 1945; Kendall, 1970); equal observations thus reduce the variance of $S$.

9 The standardized Mann-Kendall statistic $Z$ is then calculated as:

$10 \quad Z=\left\{\begin{array}{cl}\frac{S-1}{\sqrt{V(S)}} & S>0 \\ 0 & S=0 \\ \frac{S+1}{\sqrt{V(S)}} & S<0\end{array}\right.$

11 Then the probability associated with the $Z$ statistic is calculated based on the probability

12 density function for a standard normal distribution. If $Z<0$ and the calculated probability is

13 greater than the level of significance, the trend is significantly decreasing; if $Z>0$ and the

14 calculated probability is greater than the level of significance, the trend is significantly increasing. No significant trend exists if the calculated probability is less than the level of

16 significance.

The Theil-Sen approach (Theil, 1950; Sen, 1968) uses a non-parametric slope estimator based on Kendall's tau to estimate the strength of a trend. This method is

19 distribution-free and insensitive to outliers because the estimate of the slope $\beta$ is based on the median of slopes of the lines connecting $\mathrm{N}$ pairs of points $\left(i, Y_{i}\right)$ and $\left(j, Y_{j}\right)(\mathrm{Sen}, 1968)$. 
$1 \quad \beta=$ median $\left\{\frac{Y_{j}-Y_{i}}{j-i}\right\}$

2 where $Y_{j}$ and $Y_{i}$ are the observations at times $j$ and $i(i<j)$, respectively.

As the classical Mann-Kendall trend test (Mann, 1945; Kendall, 1970) assumes

4 independent data (random time series), fire and drought data were analyzed for autocorrelation first. On one hand positive serial correlation in a time series increases the chances of detecting a significant trend even if there is none (Cox and Stuart, 1955; Hamed and Rao, 1998), whereas on the other hand, a trend influences the strength of serial correlation (Yue et al., 2002). In the case of autocorrelated series, we followed the procedure of Yue $e t$ al. (2002) for assessing the significance of trends. Yue et al. (2002) suggest a four-step procedure for detecting trends in time series with significant positive autocorrelation: 1) remove the trend in the data if the slope estimated by the Theil-Sen approach differs from zero, 2) prewhiten the series to remove serial correlation (resulting in a residual series), 3) blend the identified trend and the residual series, and 4) apply the classical Mann-Kendall trend test to the blended series to analyze whether the trend is significant or not. burned and summer scPDSI for each BEC zone. Correlation analysis assumes independent data. As autocorrelation reduces the number of independent samples, it has to be considered when calculating the significance of the correlation between two time series. This was done by calculating the effective sample size n' according to Dawdy and Matalas (1964), as a first approximation of the number of independent samples:

$21 \quad n^{\prime}=n\left(\frac{1-r_{1} r_{1}^{\prime}}{1+r_{1} r_{1}^{\prime}}\right)$

where $r_{l}$ is the first-order correlation coefficient of one time series, and $r_{1}^{\prime}$ is the first-order correlation coefficient of the other time series (Dawdy and Matalas, 1964; 8-III, equation 8-

24 III-45). If either time series is not serially correlated, the effective sample size equals the 
1 sample size. According to Dawdy and Matalas (1964), a time series is considered random if

2 its first-order autocorrelation is not significant at the $95 \%$ level.

3 


\section{Results}

\section{Geographic distribution of fire in British Columbia}

3 The total area burned from 1920 to 2000 is largest in the BWBS zone (northeastern BC,

4 Figure 1) followed by the ESSF (subalpine elevations), SBS and ICH zone in interior BC

5 (Table 1, Figure 1); these are the largest zones by land area. When accounting for the

6 differences in BEC zone size, the highest proportions of flammable area burned during

7 1920-2000 occurred at lower and middle elevations in the interior (ICH, PP, IDF, MS zones)

8 and in northeastern BC (BWBS zone; Table 1) whereas the lowest total proportion of

9 flammable area burned occurred in the alpine and maritime montane zones (CMA, MH,

10 BAFA, IMA; Table 1).

Regime shift analyses

In order to obtain an estimate of the mapping completeness of the BEC zones, fire frequency

14 was analyzed for shifts in the mean according to the regime shift detection analysis of

15 Rodionov (2006). Only the three most northern zones show a significant abrupt increase in the mean (BAFA: 1958; BWBS: 1943; SWB: 1956) suggesting incomplete mapping in previous years in these remote areas. This mapping bias is equally reflected in a significant positive shift of mean area burned.

Trends in fire frequency and area burned

21 Area burned of three zones (CDF, ICH, MS), and fire frequency of seven zones (CDF, $\mathrm{CWH}$, 22 ICH, IDF, MS, SBPS, SBS) and the province of BC show significant positive autocorrelation 23 in lag 1. For these time series the procedure of Yue et al. (2002) was applied. Over the period 24 1920-2000, fire frequency and area burned show a significant negative trend in 11 and 10 out 
1 of 16 BEC zones, respectively (see Figures 2 and 3 as examples) and for the aggregated

2 statistics for BC (Table 4). This trend is strongest in the ICH and the IDF that are

3 predominantly located at low- to mid-elevations in southeastern interior BC (Table 4). The

4 CWH (lower elevations of coastal BC) and the SBS (interior plateau of BC) show a relatively

5 strong decrease in fire frequency as well (Table 4). The significant negative trend in both fire

6 frequency and area burned is weakest in IMA zone. The CMA and the MH (montane

7 elevations of coastal BC) do not show a significant trend in area burned or fire frequency

8 (Table 4). The decrease in area burned is not significant in the BG zone (driest valleys of

9 southern interior BC) either (Table 4).

10 Owing to the above-mentioned mapping bias in the three most northern zones (BAFA, SWB,

11 BWBS), zone trends in fire frequency observed over the period 1920-2000 should be

12 interpreted with caution (see Discussion). When analyzing the period after the shift, the three most northern zones (BAFA, BWBS, SWB) show a decrease in both fire frequency and area burned. The decreasing trends are statistically significant for fire frequency and area burned in the BWBS zone, and for area burned in the BAFA zone.

\section{Trends in summer SCPDSI and summer Al}

18 Summer scPDSI data for all zones and the province of BC show significant positive autocorrelation in lag 1. The summer scPDSI shows a positive trend for the province of BC and in all BEC zones, indicating that summers are getting wetter during the period 1920-2000 (Table 5; see Figures 2 and 3 as examples). According to the Mann-Kendall trend test, this trend is significant for BC and in all but the SBPS zone located on the high Fraser Plateau and the southernmost Nechako Plateau in central interior BC and extending onto the leeward slopes of the Coast Mountains (Table 5). The trend in summer scPDSI is strongest in the CDF located in the rain shadow of Vancouver Island and the ICH (lower to middle 
1 elevations in southern interior $\mathrm{BC}$ ), while it is weakest in the moist coastal zones CMA, CWH

2 and MH (low to alpine elevations on the windward side of the Coast Mountains) and in the

3 dry valleys of southern interior BC (BG, PP zones; Figure 4). zones (Table 6) and the trend towards wetter summers for the period 1920-2000 is indicated by the summer AI as well (Table 5).

Relationship between area burned and summer scPDSI

9 Spearman rank correlations between area burned and summer scPDSI are significantly negative for all but the BG zone located in the driest valleys of southern interior BC (Table 7).

11 This suggests that the decrease in area burned over the study period is related in part to

12 increasingly wetter summers for most of BC. The relationship is strongest at lower to middle

13 elevations and uppermost forested elevations in southern interior BC (ICH, MS and ESSF

14 zones) and weakest in the dry interior valleys of southern BC (PP zone; Table 7). For the

15 three most northern zones (BAFA, BWBS and SWB), rank correlations between area burned

16 and summer scPDSI were calculated for the period following the abrupt increase of annual

17 area burned (BAFA: 1958; BWBS: 1943; SWB: 1956; Table 7) because the steep increase in 18 area burned likely is a mapping artefact (see Discussion). 


\section{Discussion}

2

3

4

\section{Limitations}

The fire database, although exceptional in historical and geographical extent, has its limitations due to spatial and temporal variation in mapping methodologies, mapping intensity and precision. The percentage of all fires $>20$ ha that were reported and thus are contained in the database likely varied over time and space depending on fire suppression policy, available resources and techniques, as well as on remoteness of the area. Mapping of smaller fires is likely to be incomplete in remote areas as well as in earlier years (Meyn et al. 2009). Thus negative trends in area burned and fire frequency are likely underestimated. Podur et al. (2002) mention that mapping for northern British Columbia likely was only completed after 1960. There was no road access in northeastern BC north of Fort Saint-John (56 $14^{\prime} 17^{\prime \prime}$ N, $120^{\circ} \mathrm{W}$ ) prior to the construction of the Alaska Highway in 1943. Although there was sporadic use of aircraft in fire control in BC beginning in 1922, the BC Forest Branch chartered their first aircraft in 1945, with use (including for fire mapping) increasing through the 1950s (Parminter, 1986). Consistent with these considerations, regime shift analysis in our study suggests that mapping was already relatively complete in the boreal plains of northeastern BC (BWBS zone) after 1942 whereas regime shift years for the other two northern zones (BAFA 1958, SWB 1956) largely correspond to Podur et al. (2002). Fire data for these three zones should only be used for the period after the shift.

It is difficult to differentiate the effects of changes in land use, settlement, fire suppression, climate and climate change on area burned (Podur et al., 2002) and fire frequency. As in other regions of Canada (e.g. Ontario; Martell and Sun, 2008), fire suppression might have influenced area burned at least in the more populated areas of BC over recent decades. According to Pyne (2008), fire suppression in BC was effective during the 1960s and 1970s owing to sufficient resources and mild fire seasons. The SBPS zone 
1 (interior plateau of $\mathrm{BC}$ ) is the only zone showing a negative regime shift in the mean of fire

2 frequency around this time (1962) that does not translate into a shift of area burned. Land use

3 and settlement likely influenced area burned and the number of fires by providing ignition

4 sources accidentally, e.g. in the course of logging, railway construction, and mining as well as

5 by the purposeful use of fire such as for preparing rangeland (Pyne, 2008). Thus, an

6 anthropogenic amplification of negative trends in fire activity is quite possible. However,

7 expanding settlement also influenced the completeness of the data record over time as fires

8 had to be discovered in the first place to be part of the data record. In the more remote areas

9 (e.g. the three most northern zones), this mapping bias even led to positive trends in fire 10 activity (see above).

The a priori definition of fire regions based on the biogeoclimatic classification system of $\mathrm{BC}$ allows classifying the province into spatial units according to ecological criteria. This approach represents a top-down approach based on the assumption that trends in fire and drought are zone-specific. This is plausible because BEC zones represent landscape types with a broadly homogeneous natural vegetation and climate (Meyn et al. 2009). A disadvantage of this top-down approach may be that for fragmented zones such as the BAFA or for zones with a very large north-south extension such as the ESSF, this assumption implies that temporal fire and drought patterns are the same in northern as in southern BC. Another problem may be the assumption of spatial stationarity of the BEC zones over time. Precipitation and temperature data gridded at $400 \mathrm{~m}$ for 81 years provide complete coverage of BC. One should keep in mind, however, that they are based on interpolation and modeling of a relatively small number of weather stations, especially at high elevations and in remote areas. Weather stations were also sparser in earlier times. Nevertheless, these data are the best and most detailed surface weather data covering all of BC that are currently available (Meyn et al. 2009). 


\section{Trends in fire frequency and area burned, and regime shift analysis}

2 As fire frequency and area burned are closely related (Spearman rank correlation coefficient

$3>0.82$ for all zones and for BC), negative trends in fire frequency and area burned found for

$4 \mathrm{BC}$ and most of BC's BEC zones contrast the trend of increasing area burned in recent

5 decades that has been reported for Canada (e.g. Van Wagner, 1988; Podur et al., 2002; Stocks

6 et al., 2003; Gillett et al., 2004). Our results agree with Masters (1990) and Taylor et al.

7 (2006) reporting a decrease in area burned after 1928 in BC's southern Rocky Mountains and

8 BC's pine forests, respectively. Temporal trends are highly dependent on the period of

9 investigation as well as on the degree of smoothing especially when analyzing time series

10 with high short-term variability such as fire data. Further reasons for discrepancies include the 11 spatial resolution and the variables used for projections ( Flannigan et al., 1998; Girardin and Mudelsee, 2008;). When analyzing area burned in the BEC zones for the same period

13 (1953-95) as Skinner et al. (1999), a significant trend only occurs in the CDF zone, located in the rain shadow of Vancouver Island (results not shown). This is largely consistent with the work of Skinner et al. (1999) who found no indication of change for western Canada (aggregated statistic for BC and Alberta). The fact that in the present study the aggregated statistics for BC show a significant decrease in fire frequency and area burned in the period 1920-2000 while some BEC zones do not (Table 4) shows that a higher spatial resolution gives a more differentiated picture especially in regions with complex terrain, land use and settlement history such as BC. The higher spatial resolution also allows us to identify differences in the strength of the trend. In addition, positive regime shifts in the mean of fire frequency and area burned as detected in the three most northern zones that indicate incomplete mapping in earlier years would remain undiscovered when working at coarser 24 scales. 
2 Our results indicate a significant decrease in summer drought during the period 1920-2000 in

3 the province of $\mathrm{BC}$ and in all but one BEC zone (Table 5). This agrees with Girardin and

4 Wotton (2009) who found a wetting trend for summer moisture in western Canada over the

$520^{\text {th }}$ century. For the CWH, this is consistent with Bootsma (1994) who found that the forage

6 AI over the growing season showed a significant decline over the period 1892-1989 at

7 Agassiz (located in the Fraser Valley), indicating wetter growing seasons. For southern BC, wetting trends identified in this study are largely consistent with Andreadis and Lettenmaier (2006), who found that soil moisture and runoff increased in the northwestern U.S. in the 20th century. Xiao and Zhuang (2007) found a summer drying trend in forest regions in Canada and Alaska including BC over the period 1959-99. When we analyzed the period 1959-99 for trends (results not shown), only the SBS zone showed a significant drying trend in summer. Possible reasons for this discrepancy include differences in the spatial resolution with Canada + Alaska based on $0.5^{\circ}$ grids (Xiao and Zhuang, 2007), whereas our study is based on 16 BEC zones using 400-m spatial resolution data, and the definition of summer as May-August (Xiao and Zhuang 2007) v. June-August in our study. Although the wetting trend captured by the mean summer scPDSI for the province of BC is qualitatively consistent with results for the zones, our study shows that higher spatial resolution allows spatial differentiation of the strength of trends. Summer scPDSI and summer AI are strongly correlated for all BEC zones (Table 7) and the trend towards wetter summers for the period 1920-2000 is consistently indicated by both drought indices (Table 5). Significance levels for trends in scPDSI and summer AI differ in several zones, however. This is likely due to the fact that the scPDSI integrates drought over a longer period, with the summer scPDSI also reflecting spring precipitation and storage, which is not the case for summer AI. 
2 Relationship between annual proportion burned and summer PDSI

3 Figure 2 might suggest that both fire activity and summer moisture conditions in the ESSF

4 zone are related to a low-frequency climate oscillation such as the Pacific Decadal Oscillation

5 (PDO). Analysis of the interannual variation showed, however, that the influence of climate

6 oscillations (PDO and El Niño Southern Oscillation (ENSO)) on seasonal drought is strongest

7 and extends over nearly the entire province of $\mathrm{BC}$ in winter and spring but is weak and

8 constrained to a small area in western BC in summer (Meyn et al. 2009), which is the main

9 fire season for most of BC. As fire activity is significantly related to summer drought in all

10 but one small BEC zone (BG zone, located in the driest valleys of interior BC; Meyn et al.

11 2009), the influence of climate oscillations on fire activity in BC is indirect and correlations

12 are generally weak. Only in southeastern $\mathrm{BC}$, where winter and spring moisture are

13 sufficiently reduced to result in drier summers are climate oscillations significantly correlated

14 to fire activity (Meyn et al. 2009).

15 Except for the small BG zone located in the driest valleys of southern interior BC, all BEC

16 zones and the aggregated statistic for BC show a significant negative relationship between

17 summer drought and area burned, indicating that the decrease in area burned is related to

18 wetter summers (Table 7). For the three most northern zones (BAFA, BWBS, SWB), this

19 applies to the period of relative complete mapping. These results are consistent with the

20 finding of Meyn et al. (2009) that interannual variation (as indicated by detrended time series)

21 of annual proportion burned is significantly related to summer drought in all but the small BG

22 zone. Although factors other than the wetting trend such as fire suppression and early

23 exploitation in the more accessible zones might have strengthened the trend towards fewer

24 fires and a lower area burned in recent decades, an increase in mapping quality and late

25 exploitation in the more remote zones likely has had the opposite effect. 
1 Although some studies associate an increase in temperature (global warming) with a general

2 increase in fire activity (Overpeck et al., 1990; IPCC 1996), our results suggest that this is not

3 the case for BC. Although six BEC zones (BAFA, BWBS, CMA, CWH, MH, SWB) show a

4 significant increase in summer temperature over the period 1920-2000 (results not shown),

5 these zones show a significant wetting trend (Table 5). Thus an increase in summer

6 temperatures does not necessarily cause an increase in drought and area burned owing to

7 complex and interacting influences of temperature and precipitation on fuel characteristics,

8 lightning intensity, ignition probability, drought, and fire management success.

9 


\section{Conclusions}

2 Our study shows that aggregated statistics for large administrative regions such as an entire

3 province can hide the spatial variation of the direction and strength of trends in area burned,

4 fire frequency and summer drought, and in the relationship between area burned and summer

5 drought. This seems especially valid in regions with complex relief and a variety of

6 ecosystems, with spatial variation in land use and settlement history such as BC. Results

7 suggest that the decrease in area burned and fire frequency during the period 1920-2000 is

8 significantly related to a decrease in summer drought with the strength of the relationship

9 considerably varying between BC's BEC zones. Analyses of trends for different drought

10 indices (scPDSI and AI in this study; Monthly Drought Code (MDC) in Girardin and Wotton

11 (2009)) and their relationship to fire behaviour over the 20th century consistently show a

12 trend towards lower fire activity that is related to a summer wetting trend in BC.

\section{Acknowledgements}

15 A.M. thanks the German Academic Exchange Service (DAAD) and the Stiftung der

16 deutschen Wirtschaft (sdw) for grants. We thank Pamela Cheers for reviewing the manuscript. 


\section{References}

2 Alley, W. M. (1984) The Palmer Drought Severity Index: Limitations and assumptions. Journal of Climate and Applied Meteorology, 23, 1100-1109.

Amiro, B. D., Logan, K. A., Wotton, B. M., Flannigan, M. D., Todd, J. B., Stocks, B. J. and Martell, D. L. (2004) Fire weather index system components for large fires in the Canadian boreal forest. International Journal of Wildland Fire, 13, 391-400.

Andreadis, K. M. and Lettenmaier, D. P. (2006) Trends in 20th century drought over the continental United States. Geophysical Research Letters, 33.

Bootsma, A. (1994) Long term (100 yr) climatic trends for agriculture at selected locations in Canada. Climatic Change, 26, 65-88.

Cox, D. R. and Stuart, A. (1955) Some quick sign tests for trend in location and dispersion. Biometrika, 42, 80-95.

Dai, A., Trenberth, K. E. and Qian, T. (2004) A global dataset of Palmer Drought Severity Index for 1870-2002: Relationship with soil moisture and effects of surface warming.

Flannigan, M. D., Logan, K. A., Amiro, B. D., Skinner, W. R. and Stocks, B. J. (2005) Future Journal of Hydrometeorology, 5, 1117-1130.

Daly, C., Gibson, W. P., Taylor, G. H., Johnson, G. L. and Pasteris, P. (2002) A knowledgebased approach to the statistical mapping of climate. Climate Research, 22, 99-113.

Dawdy, D. R. and Matalas, N. C. (1964) Statistical and probability analysis of hydrologic data. Part III: Analysis of variance, covariance, and time series. Handbook of applied hydrology. A compendium of water resources technology (ed. by V. Te Chow), pp. 8.68-8.90. McGraw-Hill Book Company, New York.

Flannigan, M. D., Bergeron, Y., Engelmark, O. and Wotton, B. M. (1998) Future wildfire in circumboreal forests in relation to global warming. Journal of Vegetation Science, $\mathbf{9}$, 469-476. area burned in Canada. Climatic Change, 72, 1-16. 
1 Flannigan, M. D., Stocks, B. J. and Wotton, B. M. (2000) Climate change and forest fires. The Science of the Total Environment, 262, 221-229.

Gillett, N. P., Weaver, A. J., Zwiers, F. W. and Flannigan, M. D. (2004) Detecting the effect of climate change on Canadian forest fires. Geophysical Research Letters, 31, L 18211. doi: 10.1029/2004GL020876

Girardin, M. P. and Mudelsee, M. (2008) Past and future changes in Canadian boreal wildfire activity. Ecological Applications, 18, 391-406.

Girardin, M. P. and Wotton, B. M. (2009) Summer moisture and wildfire risks across Canada. Journal of Applied Meteorology and Climatology, 48, 517-533.

Hamann, A. and Wang, T. L. (2005) Models of climatic normals for genecology and climate change studies in British Columbia. Agricultural and Forest Meteorology, 128, 211221.

Hamed, K. H. (2008) Trend detection in hydrologic data: The Mann-Kendall trend test under the scaling hypothesis. Journal of Hydrology, 349, 350-363.

Hamed, K. H. and Rao, A. R. (1998) A modified Mann-Kendall trend test for autocorrelated data. Journal of Hydrology, 204, 182-196.

Heim, R. R., Jr. (2002) A review of twentieth-century drought indices used in the United States. Bulletin of the American Meteorological Society, 83, 1149-1165.

IPCC. (1996) Climate Change 1995 Impacts, Adaptations and Mitigation of Climate Change: Scientific-technical Analyses. (ed. by I.P.O.C.C. (IPCC)). Cambridge University Press, Cambridge, U.K.

Kasischke, E. S. and Turetsky, M. R. (2006) Recent changes in the fire regime across the North American boreal region - Spatial and temporal patterns of burning across Canada and Alaska. Geophysical Research Letters, 33, L09703, doi: 10.1029/2006GL025677. 
1 Kendall, M. G. (1970) Rank correlation methods, 4th edn. Griffin London Publishing, London, U.K.

Mann, H. B. (1945) Nonparametric tests against trend. Econometrica, 13, 245-259.

Martell, D. L. and Sun, H. (2008) The impact of fire suppression, vegetation, and weather on the area burned by lightning-caused forest fires in Ontario. Canadian Journal of Forest Research, 38, 1547-1563.

Masters, A. M. (1990) Changes in forest fire frequency in Kootenay National Park, Canadian Rockies. Canadian Journal of Botany, 68, 1763-1767.

Meidinger, D. and Pojar, J. (1991) Ecosystems of British Columbia. pp 330. BC Ministry of Forests Special Report Series 6, Research Branch, BC Ministry of Forests, Victoria, B.C., Canada.

Meyn, A., Taylor, S.W., Flannigan, M.D., Thonicke, K. and Cramer, W. (2009) Relationship between fire, climate oscillations, and drought in British Columbia, Canada, 19202000. Global Change Biology, doi: 10.1111/j.1365-2486.2009.02061.x

Mitchell, T. D. and Jones, P. D. (2005) An improved method of constructing a database of monthly climate observations and associated high-resolution grids. International Journal of Climatology, 25, 693-712.

Overpeck, J. T., Rind, D. and Goldberg, R. (1990) Climate-induced changes in forest disturbance and vegetation. Nature, 343, 51-53.

Palmer, W. C. (1965) Meteorological drought. Research Paper No. 45, 58 pp. U.S. Department of Commerce Weather Bureau, Washington, D.C.

Parminter, J. V. (1986) Guardians of the sky: aircraft and their use in forestry in B.C. 19181926. Whistlepunk, 1, 3-10.

Podur, J., Martell, D. L. and Knight, K. (2002) Statistical quality control analysis of forest fire activity in Canada. Canadian Journal of Forest Research, 32, 195-205.

Pyne, S. J. (2008) Awful splendour: A fire history of Canada, University of British Columbia, Vancouver, B.C., Canada. 
1 Research Branch, BC Ministry of Forests and Range (2006a) Provincial Biogeoclimatic Subzone/Variant Mapping, Version 6

'Research Branch, BC Ministry of Forests and Range (2006b) Provincial Biogeoclimatic Subzone/Variant Mapping with Generalized Land Cover, Version 6

Rodionov, S. N. (2006) Use of prewhitening in climate regime shift detection. Geophysical Research Letters, 33, L12707, doi: 10.1029/2006GL025904.

Sen, P. K. (1968) Estimates of the regression coefficient based on Kendalls's tau. Journal of the American Statistical Association, 63, 1379-1389.

Shabbar, A. and Skinner, W. (2004) Summer drought patterns in Canada and the relationship to global sea surface temperatures. Journal of Climate, 17, 2866-2880.

Skinner, W. R., Stocks, B. J., Martell, D. L., Bonsal, B. and Shabbar, A. (1999) The association between circulation anomalies in the mid-troposphere and area burned by wildland fire in Canada. Theoretical and Applied Climatology, 63, 89-105.

Stocks, B. J., Fosberg, M. A., Lynham, T. J., Mearns, L., Wotton, B. M., Yang, Q., Jin, J. Z., Lawrence, K., Hartley, G. R., Mason, J. A. and McKenney, D. W. (1998) Climate change and forest fire potential in Russian and Canadian boreal forests. Climatic Change, 38, 1-13.

Stocks, B. J., Mason, J. A., Todd, J. B., Bosch, E. M., Wotton, B. M., Amiro, B. D., Flannigan, M. D., Hirsch, K. G., Logan, K. A., Martell, D. L. and Skinner, W. R. (2003) Large forest fires in Canada, 1959-1997. Journal of Geophysical ResearchAtmospheres, 108, D1, 8149, doi: 10.1029/2001JD000484.

Taylor, S. W., Carroll, A. L., Alfaro, R. I. and Safranyik, L. (2006) Forest, climate and mountain pine beetle outbreak dynamics in western Canada. The Mountain Pine Beetle: A synthesis of biology, management, and impacts in Lodgepole Pine, (ed. by L. Safranyik and W.R. Wilson), pp 67-94. Natural Ressources Canada, Canadian Forest Service, Pacific Forestry Centre, Victoria, B.C. 
Taylor, S. W. and Thandi, G. (2003) Development and Analysis of a Provincial Natural Disturbance Database. pp 34. Pacific Forestry Centre, Natural Resources Canada, Victoria, B.C.

Theil, H. (1950) A rank-invariant method of linear and polynomial regression analysis. Indagationes Mathematicae, 12, 85-91.

Thornthwaite C. W. (1948) An approach toward a rational classification of climate. Geographical Review, 38, 55-94.

United Nations Environment Programme (UNEP). (1992) World atlas of desertification, Edward Arnold, London, U.K.

van der Schrier, G., Briffa, K. R., Jones, P. D. and Osborn, T. J. (2006) Summer moisture variability across Europe. Journal of Climate, 19, 2818-2834.

van der Schrier, G., Efthymiadis, D., Briffa, K. R. and Jones, P. D. (2007) European Alpine moisture variability for 1800-2003. International Journal of Climatology, 27, 415427.

Van Wagner, C. E. (1988) The historical pattern of annual burned area in Canada. The Forestry Chronicle, 64, 182-185.

Wang, T., Hamann, A., Spittlehouse, D. L. and Aitken, S. N. (2006) Development of scalefree climate data for western Canada for use in resource management. International Journal of Climatology, 26, 383-397.

Webb, R. S., Rosenzweig, C. E. and Levine, E. R. (1993) Specifying land surface characteristics in general circulation models: soil profile data set and derived waterholding capacities. Global Biogeochemical Cycles, 7, 97-108.

Wells, N., Goddard, S. and Hayes, M. J. (2004) A self-calibrating Palmer Drought Severity Index. Journal of Climate, 17, 2335-2351.

Wotton, B. M. and Flannigan, M. D. (1993) Length of the fire season in a changing climate. The Forestry Chronicle, 69, 187-192. 
1 Xiao, J. and Zhuang, Q. (2007) Drought effects on large fire activity in Canadian and Alaskan forests. Environmental Research Letters, 2, 044003, doi: 10.1088/1748-

3 9326/2/4/044003.

4 Yue, S., Pilon, P., Phinney, B. and Cavadias, G. (2002) The influence of autocorrelation on 5 the ability to detect trend in hydrological series. Hydrological Processes, 16, 1807-

6 1829.

7 


\section{Tables}

2 Table 1. Biogeoclimatic Ecosystem Classification (BEC) zones of British Columbia and geographic distribution

3 of fire (modified after Meyn et al. 2009). For a short introduction to the BEC zones see Supplementary

4 information 1.

\begin{tabular}{lccccc}
\hline & & & Total area & Percentage of \\
& Total & Percentage & burned & flammable area \\
Biogeoclimatic zone & size in & of flammable & $1920-2000$ & burned by fires $>$ \\
& BC & land per & by fires $>$ & 20 during \\
& & zone & $20 \mathrm{ha}$ & $1920-2000$
\end{tabular}

\begin{tabular}{|c|c|c|c|c|c|}
\hline $\begin{array}{l}\text { Abbre- } \\
\text { viation }\end{array}$ & Full Name & {$[\%]$} & {$[\%]$} & {$\left[\mathrm{km}^{2}\right]$} & {$[\%]$} \\
\hline BAFA & Boreal Altai Fescue Alpine & 7.9 & 89.1 & 577.2 & 0.9 \\
\hline $\mathrm{BG}$ & Bunchgrass & 0.3 & 90 & 226.0 & 8.9 \\
\hline BWBS & $\begin{array}{c}\text { Boreal White and Black } \\
\text { Spruce }\end{array}$ & 16.5 & 97.7 & 31867.7 & 20.8 \\
\hline $\mathrm{CDF}$ & Coastal Douglas-fir & 0.3 & 98.4 & 374.1 & 14.6 \\
\hline CMA & $\begin{array}{c}\text { Coastal Mountain-heather } \\
\text { Alpine }\end{array}$ & 4.6 & 55.6 & 115.2 & 0.5 \\
\hline $\mathrm{CWH}$ & Coastal Western Hemlock & 11.4 & 96.7 & 6709.9 & 6.4 \\
\hline ESSF & $\begin{array}{c}\text { Engelmann Spruce - } \\
\text { Subalpine Fir }\end{array}$ & 18.0 & 99 & 14507.5 & 8.6 \\
\hline $\mathrm{ICH}$ & Interior Cedar - Hemlock & 5.8 & 94.2 & 12184.2 & 23.5 \\
\hline IDF & Interior Douglas-fir & 4.7 & 96.8 & 7699.6 & 18.0 \\
\hline IMA & $\begin{array}{l}\text { Interior Mountain-heather } \\
\text { Alpine }\end{array}$ & 1.7 & 67.1 & 150.0 & 1.4 \\
\hline $\mathrm{MH}$ & Mountain Hemlock & 3.7 & 97.1 & 292.5 & 0.8 \\
\hline MS & Montane Spruce & 3.0 & 99.2 & 5574.2 & 19.9 \\
\hline $\mathrm{PP}$ & Ponderosa Pine & 0.4 & 92.6 & 787.4 & 22.8 \\
\hline SBPS & Sub-Boreal Pine - Spruce & 2.5 & 97.5 & 2868.6 & 12.6 \\
\hline
\end{tabular}




\begin{tabular}{cccccc}
\hline SBS & Sub-Boreal Spruce & 10.9 & 93.4 & 13714.5 & 14.2 \\
\hline SWB & Spruce - Willow - Birch & 8.4 & 98.7 & 6091.7 & 7.7
\end{tabular}

1 * In this study, land covered by permanent ice and snow or by freshwater was considered as not flammable.

2

3

4 Table 2: Classification of Palmer Drought Severity Index (PDSI) values according to Palmer (1965)

\begin{tabular}{cc}
\hline PDSI value & PDSI category \\
\hline $3.00-3.99$ & Extreme wet spell \\
$2.00-2.99$ & Moderate wet spell \\
$1.00-1.99$ & Mild wet spell \\
$0.50-0.99$ & Incipient wet spell \\
$0.49--0.49$ & Normal \\
$-0.50--0.99$ & Incipient drought \\
$-1.00--1.99$ & Mild drought \\
$-2.00--2.99$ & Moderate drought \\
$-3.00--3.99$ & Severe drought \\
$<-4.00$ & Extreme drought \\
\hline
\end{tabular}

5

6

7 Table 3: Classes of the Aridity Index (AI) according to United Nations Environment Programme (1992).

\begin{tabular}{cc}
\hline Category & Aridity Index \\
\hline Hyperarid & $\mathrm{AI}<0.05$ \\
\hline arid & $0.05<\mathrm{AI}<0.20$ \\
\hline semi-arid & $0.20<\mathrm{AI}<0.50$ \\
\hline dry subhumid & $0.50<\mathrm{AI}<0.65$ \\
\hline moist subhumid & $0.65<\mathrm{AI}<1.0$ \\
\hline humid & $\mathrm{AI}>1$ \\
\hline
\end{tabular}


Table 4: Trends in annual proportion of flammable area that burned ('area burned') and fire frequency in BC's BEC zones 1920-2000. Significance of trends was calculated according to the Mann-Kendall trend test (MK; Mann, 1945; Kendall, 1970); for time-series with significant positive autocorrelation in lag 1, significance was calculated according to the Mann-Kendall trend test based on Yue et al.'s (2002) procedure for autocorrelated data. Magnitude of trends is based on Theil-Sen (TS) estimate of slope $\beta$ (Sen, 1968).

\begin{tabular}{|c|c|c|c|c|}
\hline \multirow{3}{*}{$\begin{array}{c}\text { Biogeoclimatic } \\
\text { zone }\end{array}$} & \multicolumn{2}{|c|}{ Area burned } & \multicolumn{2}{|c|}{ Fire frequency } \\
\hline & MK: Significance & TS slope & MK: Significance & TS slope \\
\hline & of trend (p) & $\beta$ & of trend $(p)$ & $\beta$ \\
\hline Province of $\mathrm{BC}^{\mathrm{b}}$ & $0.0000 * * *$ & -0.001900 & $0.0000 * * *$ & -8.666667 \\
\hline $\mathrm{BAFA}^{1}$ & 0.1844 n.s. & 0.000000 & $0.0386 *$ & 0.000000 \\
\hline BG & 0.3356 n.s. & -0.000203 & $0.0228 *$ & -0.055556 \\
\hline $\mathrm{BWBS}^{2}$ & $0.0439 *$ & 0.000443 & $0.0046 * *$ & 0.461538 \\
\hline $\mathrm{CDF}^{\mathrm{ab}}$ & $0.0286 *$ & -0.001493 & $0.0032 * *$ & -0.146700 \\
\hline CMA & 0.5975 n.s. & 0.000000 & 0.4550 n.s. & 0.000000 \\
\hline $\mathrm{CWH}^{\mathrm{b}}$ & $0.0000 \quad * * *$ & -0.001183 & $0.0000 * * *$ & -1.175338 \\
\hline ESSF & $0.0001 * * *$ & -0.001083 & 0.0007 *** & -0.692308 \\
\hline $\mathrm{ICH}^{\mathrm{ab}}$ & $0.0048 \quad * *$ & -0.003145 & 0.0003 *** & -1.409470 \\
\hline $\mathrm{IDF}^{\mathrm{b}}$ & $0.0000 \quad * * *$ & -0.002543 & $0.0000 * * *$ & -1.450553 \\
\hline IMA & $0.0001 \quad * * *$ & -0.000098 & $0.0006 * * *$ & -0.026671 \\
\hline $\mathrm{MH}$ & 0.0681 n.s. & -0.000024 & 0.0778 n.s. & -0.025978 \\
\hline $\mathrm{MS}^{\mathrm{ab}}$ & $0.0122 *$ & -0.001468 & 0.0008 *** & -0.430704 \\
\hline PP & $0.0005 \quad * * *$ & -0.002284 & 0.0002 *** & -0.204605 \\
\hline SBPS $^{b}$ & $0.0001 \quad * * *$ & -0.000736 & $0.0081 * *$ & -0.129331 \\
\hline $\mathrm{SBS}^{\mathrm{b}}$ & $0.0000 \quad * * *$ & -0.001134 & $0.0002 * * *$ & -1.000000 \\
\hline SWB & $0.0000 \quad * * *$ & 0.000235 & $0.0000 * * *$ & 0.084926 \\
\hline
\end{tabular}

6 n.s.=not significant, $*=\mathrm{p}<0.05, * *=\mathrm{p}<0.01, * * *=\mathrm{p}<0.001, \mathrm{a}=$ significant positive autocorrelation in area

7 burned in lag $1 ; b=$ significant positive autocorrelation in fire frequency in lag $1 ;{ }^{1}$ In BAFA, area burned shows 
1 a significant negative trend for the period of complete mapping (1958-2000). ${ }^{2}$ In BWBS, both area burned and

2 fire frequency show a significant negative trend for the period of complete mapping (1944-2000).

3 
1 Table 5. Trends in summer self-calibrating Palmer Drought Severity Index (scPDSI) and summer aridity index

2 (AI) in BC's BEC zones 1920-2000. Significance of trends according to the Mann-Kendall trend test (MK;

3 Mann, 1945; Kendall, 1970) was calculated based on Yue et al.'s (2002) procedure for autocorrelated data.

4 Magnitude of trends is based on Theil-Sen (TS) estimate of slope $\beta$ (Sen, 1968). The AI is defined as AI =

$5 \quad \mathrm{P} / \mathrm{PET}$ where $\mathrm{P}$ is the monthly precipitation in $\mathrm{mm}$ and PET is the monthly potential evapotranspiration in $\mathrm{mm}$

6 (United Nations Environment Programme (UNEP), 1992).

\begin{tabular}{|c|c|c|c|c|}
\hline & \multicolumn{2}{|c|}{ Summer scPDSI } & \multicolumn{2}{|c|}{ Summer AI } \\
\hline Biogeoclimatic & MK (p) & TS slope & MK (p) & TS slope \\
\hline zone & & $\beta$ & & $\beta$ \\
\hline Province of $\mathrm{BC}^{\mathrm{a}}$ & $* * *$ & 0.002 & ** & 0.003 \\
\hline $\mathrm{BAFA}^{\mathrm{a}}$ & $* \star *$ & 0.029 & $\mathrm{p}<0.10$ & 0.001 \\
\hline $\mathrm{BG}^{\mathrm{a}}$ & * & 0.021 & ** & 0.002 \\
\hline $\mathrm{BWBS}^{\mathrm{a}}$ & ** & 0.035 & $\mathrm{p}<0.10$ & 0.001 \\
\hline $\mathrm{CDF}^{\mathrm{a}}$ & $* * *$ & 0.042 & * & 0.003 \\
\hline $\mathrm{CMA}^{\mathrm{a}}$ & ** & 0.022 & n.s. & 0.002 \\
\hline $\mathrm{CWH}^{\mathrm{a}}$ & ** & 0.025 & ** & 0.003 \\
\hline $\mathrm{ESSF}^{\mathrm{a}}$ & $\star \star \star *$ & 0.035 & 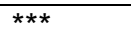 & 0.003 \\
\hline $\mathrm{ICH}^{\mathrm{a}}$ & $* * *$ & 0.037 & * & 0.001 \\
\hline $\mathrm{IDF}^{\mathrm{a}}$ & $* * *$ & 0.034 & ** & 0.003 \\
\hline IMA $^{\mathrm{a}}$ & 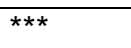 & 0.035 & * & 0.003 \\
\hline $\mathrm{MH}^{\mathrm{a}}$ & ** & 0.023 & ** & 0.002 \\
\hline $\mathrm{MS}^{\mathrm{a}}$ & 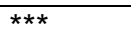 & 0.033 & ** & 0.001 \\
\hline $\mathrm{PP}^{\mathrm{a}}$ & ** & 0.024 & ** & 0.002 \\
\hline SBPS $^{\mathrm{a}}$ & n.s & 0.026 & * & 0.002 \\
\hline $\mathrm{SBS}^{\mathrm{a}}$ & ** & 0.034 & ** & 0.002 \\
\hline $\mathrm{SWB}^{\mathrm{a}}$ & ** & 0.029 & ** & 0.003 \\
\hline
\end{tabular}

7 n.s. $=$ not significant, $*=p<0.05, * *=p<0.01, * * *=p<0.001, a=$ significant positive autocorrelation in summer

$8 \quad$ scPDSI in lag 1 
1 Table 6. Spearman rank correlation between summer scPDSI and summer AI in BC's biogeoclimatic zones

2 1920-2000. Since summer AI data do not show significant autocorrelation, no adjustment of significance levels

3 is necessary.

\begin{tabular}{|c|c|}
\hline Biogeoclimatic zone & Spearman rank $r$ \\
\hline BAFA & $0.54 * * *$ \\
\hline $\mathrm{BG}$ & $0.43 * * *$ \\
\hline BWBS & $0.62 * * *$ \\
\hline $\mathrm{CDF}$ & $0.56 * * *$ \\
\hline CMA & $0.55 * * *$ \\
\hline $\mathrm{CWH}$ & $0.59 * * *$ \\
\hline ESSF & $0.62 * * *$ \\
\hline $\mathrm{ICH}$ & $0.66 * * *$ \\
\hline IDF & $0.51 * * *$ \\
\hline IMA & $0.65 * * *$ \\
\hline $\mathrm{MH}$ & $0.55 * * *$ \\
\hline MS & $0.58 * * *$ \\
\hline $\mathrm{PP}$ & $0.45 * * *$ \\
\hline SBPS & $0.57 * * *$ \\
\hline SBS & $0.52 * * *$ \\
\hline SWB & $0.57 * * *$ \\
\hline
\end{tabular}

4

n.s.=not significant, $*=\mathrm{p}<0.05, * *=\mathrm{p}<0.01, * * *=\mathrm{p}<0.001$

5 
1 Table 7. Spearman rank correlation between annual proportion of flammable area burned ('area burned') and

2 summer drought (scPDSI and summer AI, respectively) in BC's biogeoclimatic zones 1920-2000. 'Significance

3 levels are adjusted for autocorrelation based on equivalent sample size of Dawdy and Matalas (1964).

\begin{tabular}{|c|c|c|}
\hline Biogeoclimatic zone & $\begin{array}{c}\text { Spearman rank } r \text { with } \\
\text { summer scPDSI }\end{array}$ & $\begin{array}{c}\text { Spearman rank } \mathbf{r} \text { with } \\
\text { summer AI }\end{array}$ \\
\hline Province of $\mathrm{BC}$ & $-0.58 * * *$ & $-0.51 * * *$ \\
\hline BAFA (1958-2000) & $-0.44 * *$ & $-0.43 * *$ \\
\hline BG & -0.20 n.s. & -0.22 n.s. \\
\hline BWBS (1943-2000) & $-0.43 * * *$ & $-0.37 * *$ \\
\hline $\mathrm{CDF}^{\mathrm{a}}$ & $-0.59 * * *$ & $-0.37 * * *$ \\
\hline CMA & $-0.39 * * *$ & $-0.39 * * *$ \\
\hline $\mathrm{CWH}$ & $-0.53 * * *$ & $-0.50 * * *$ \\
\hline ESSF & $-0.61 * * *$ & $-0.65 * * *$ \\
\hline $\mathrm{ICH}^{\mathrm{a}}$ & $-0.73 * * *$ & $-0.75 * * *$ \\
\hline IDF & $-0.54 * * *$ & $-0.64 * * *$ \\
\hline IMA & $-0.51 * * *$ & $-0.60 * * *$ \\
\hline $\mathrm{MH}$ & $-0.49 * * *$ & $-0.53 * * *$ \\
\hline $\mathrm{MS}^{\mathrm{a}}$ & $-0.67 * * *$ & $-0.71 * * *$ \\
\hline $\mathrm{PP}$ & $-0.34 * *$ & $-0.59 * * *$ \\
\hline SBPS & $-0.38 * * *$ & $-0.45 * * *$ \\
\hline SBS & $-0.60 * * *$ & $-0.59 * * *$ \\
\hline SWB (1956-2000) & $-0.42 * *$ & $-0.43 * *$ \\
\hline
\end{tabular}

4 n.s.=not significant, $*=\mathrm{p}<0.05, * *=\mathrm{p}<0.01, * * *=\mathrm{p}<0.001, \mathrm{a}=$ significant positive autocorrelation of area 5 burned in lag 1 


\section{Figure legends}

2 Figure 1. Biogeoclimatic zones of British Columbia. BAFA: Boreal Altai Fescue Alpine; BG: Bunchgrass;

3 BWBS: Boreal White and Black Spruce; CDF: Coastal Douglas-fir; CMA: Coastal Mountain-heather Alpine;

4 CWH: Coastal Western Hemlock; ESSF: Engelmann Spruce-Subalpine Fir; ICH: Interior Cedar-Hemlock; IDF:

5 Interior Douglas-fir; IMA: Interior Mountain-heather Alpine; MH: Mountain Hemlock; MS: Montane Spruce;

6 PP: Ponderosa Pine; SBPS: Sub-Boreal Pine-Spruce; SBS: Sub-Boreal Spruce; SWB: Spruce-Willow-Birch.

7 Zones are according to Research Branch, BC Ministry of Forests and Range (2006b). White areas represent non-

8 flammable areas (permanent ice and snow, freshwater), which were excluded from the analysis. PG: City of

9 Prince George. V: City of Vancouver.

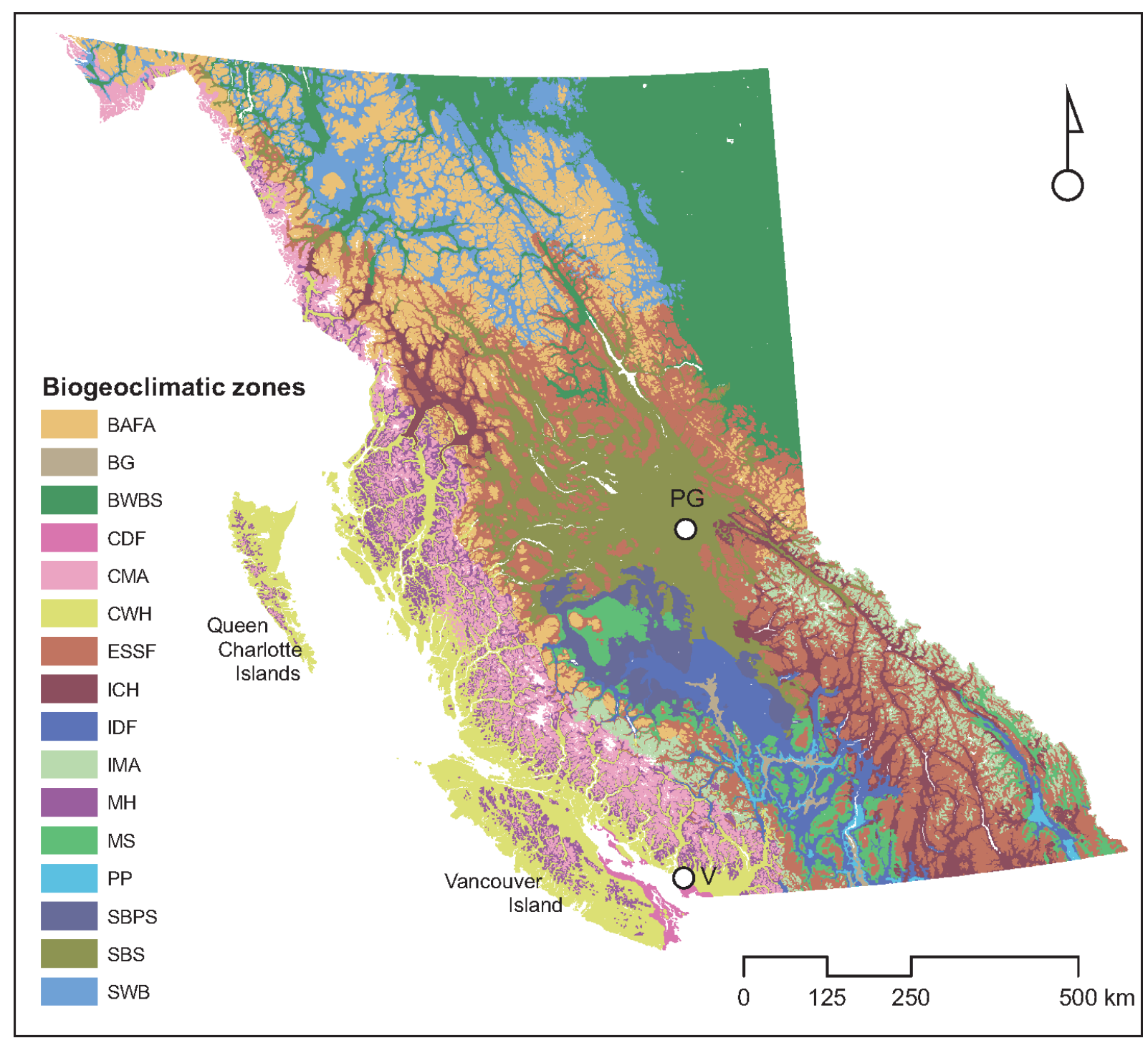


1 Figure 2. Summer self-calibrating Palmer Drought Severity Index (scPDSI) and annual proportion burned in the

2 ESSF zone 1920-2000. Straight lines represent linear trends.

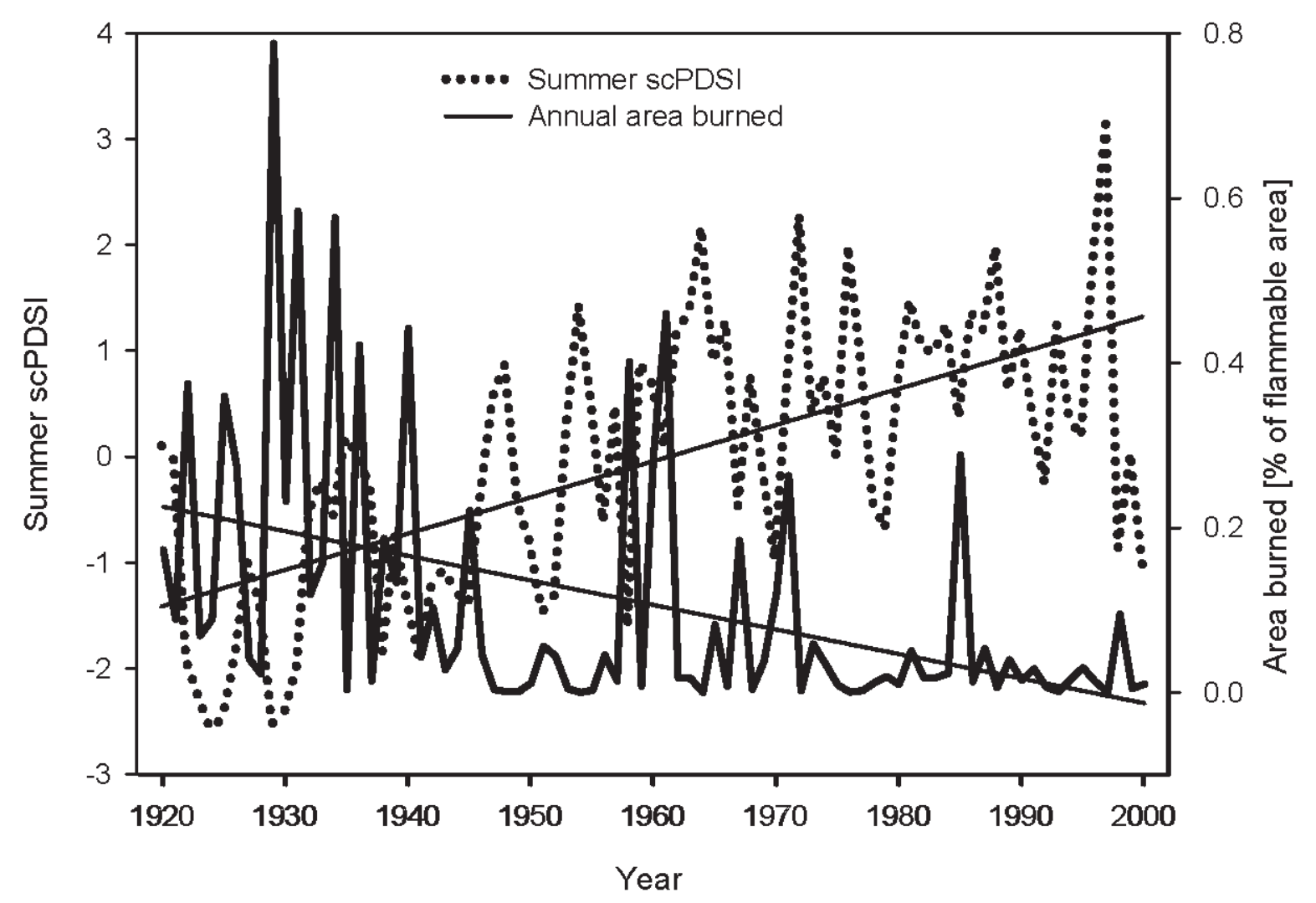


1 Figure 3. Summer self-calibrating Palmer Drought Severity Index (scPDSI) and annual proportion burned in the

2 BG zone 1920-2000. Straight lines represent linear trends.

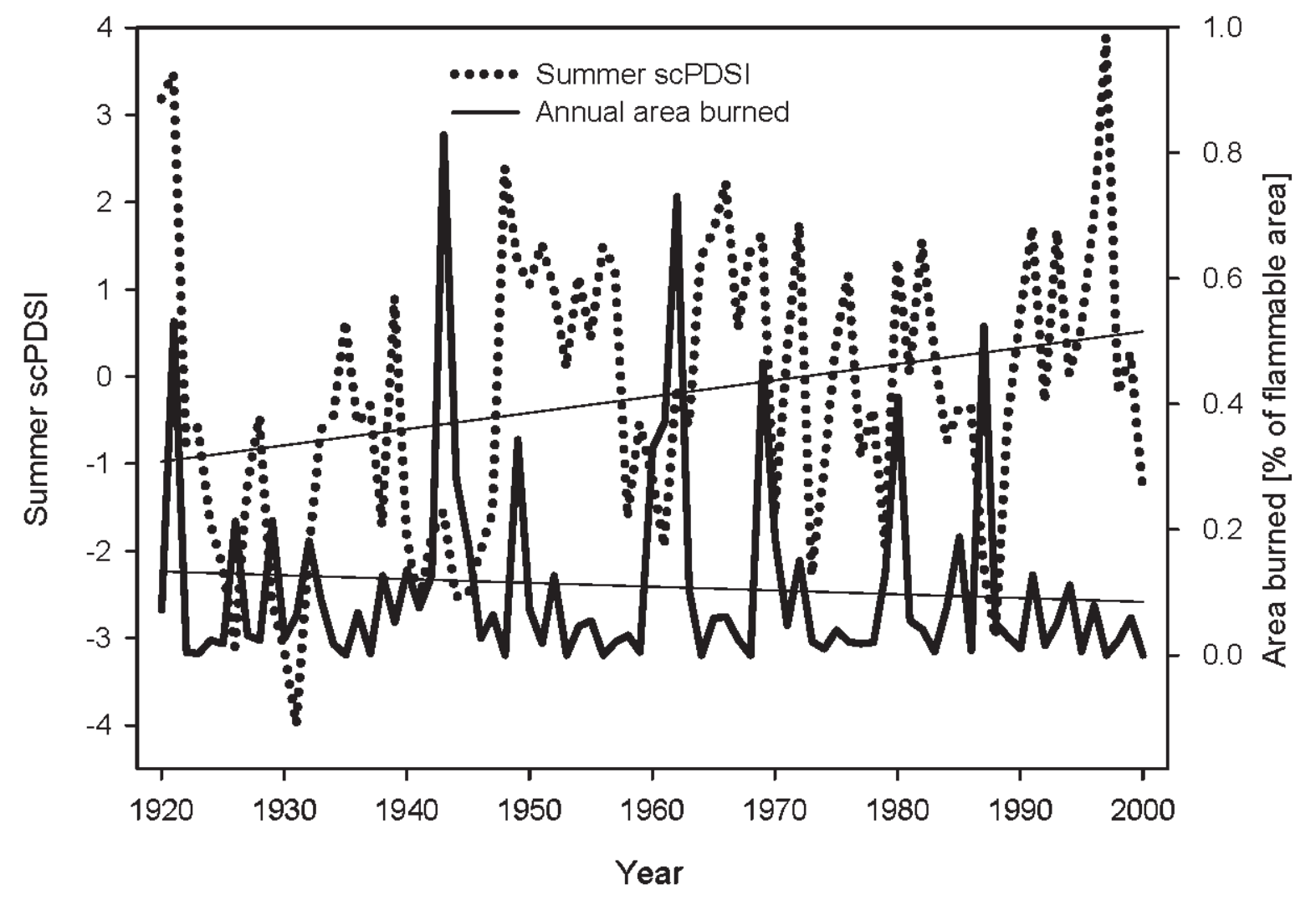

3 
1 Figure 4. Spatial patterns of strength in trends of summer self-calibrating Palmer Drought Severity Index

2 (scPDSI). White areas represent non-flammable areas (permanent ice and snow, freshwater), which were

3 excluded from the analysis. V: City of Vancouver; PG: City of Prince George.

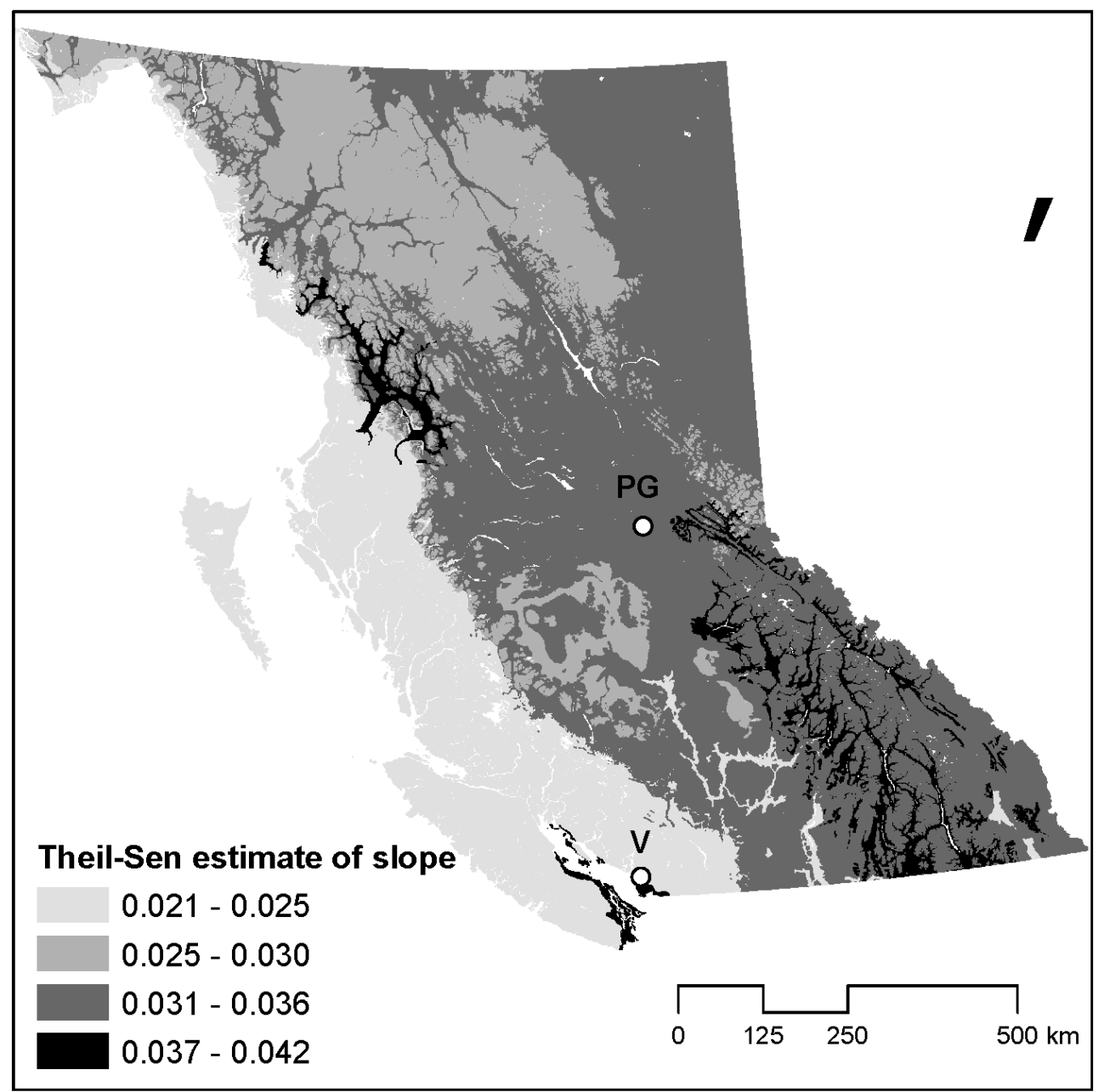

